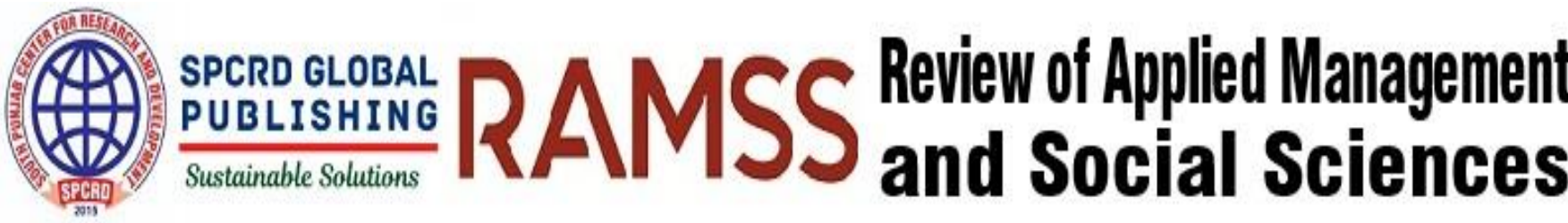

\section{Environmental Quality and Economic Status of Households in Pakistan: A Case Study of Multan District}

\author{
${ }^{a}$ Furrukh Bashir, ${ }^{b}$ Haseeb-Ur-Rehman, ${ }^{c}$ Kishwar Parveen \\ a Assistant Professor, School of Economics, Bahauddin Zakariya University, Multan, Pakistan: furrukh@bzu.edu.pk \\ ${ }^{\mathrm{b}}$ M. Phil. Scholar, School of Economics, Bahauddin Zakariya University, Multan, Pakistan \\ ${ }^{c}$ Visiting Lecturer, School of Economics, Bahauddin Zakariya University, Multan, Pakistan \\ Corresponding author's email address: furrukh@bzu.edu.pk
}

\begin{tabular}{l}
\hline ARTICLE DETAILS \\
\hline History: \\
Accepted o7 December 2019 \\
Available online 31 December 2019
\end{tabular}

Keywords:

Earnings, Expenditure, Assets, Multan District, Green Belt \& Trees, Health Facilities, Irrigation Facility, Clean Drinking Water, Sui Gas

\section{JEL Classification:}

D31, D33, E25, O15

DOI: $10.47067 /$ ramss.v2i2.16

\begin{abstract}
The present study is aiming to identify the effect of Environmental Quality on the Economic Status of Households (Income, Expenditure and Assets) in Multan District of Southern Punjab, Pakistan. The results of OLS demonstrates that Age, Education, Formal Employment, Green Belt \& Trees, Health Facilities, Irrigation Facility, Clean Drinking Water, Sui Gas Availability and Housing Condition are reported as the basis of Higher Income/ Expenditure of Households while Rural Area, Female to Male ratio and credit availability are reducing Income/ Expenditure of Households. On the other side, Age, Education, Rural Location, Formal Employment, Credit Availability, Green Belt \& Trees, Health Facilities, Irrigation Facility, Clean Drinking Water, Sui Gas Availability and Housing Condition are the origin of increasing Assets of Households while Female to male ratio is reducing Assets.
\end{abstract}

(C) 2019 The authors. Published by SPCRD Global Publishing. This is an open access article under the Creative Commons Attribution-

NonCommercial 4.0

\section{Introduction}

Environmental degradation in the developing countries is the major problem which is being caused by the industrial revolution. Industrial revolution is resulting different types of pollution like Liquid pollution, solid pollution and gas pollution and noise pollution. All the developed countries are also facing these problems but they have made certain legislations to overcome the environmental problems. In $3^{\text {rd }}$ world countries, Environmental degradation problems are more than the developing countries. Due to these countries the Human Development Index has decreased. Poor Health, Poverty and Low income is also the result of Environmental degradation. Any country cannot attain the macroeconomic goal without concentrating on the environment. Various economists have paid attention towards the environment protection and environmental up-gradation which is having close and tied relationship with development. Moreover, environment is also linked with health and education. 
Literacy rate, health facilities, clean drinking water, clean environment, sewerage condition, houses conditions, forest, drainage systems are in very low conditions in Pakistan and due to these, environmental problems are continuously increasing. These environmental problems are in response of liquid pollution, solid pollution, Gas pollution, deforestation, poor drainage system etc. After the emergence, Government of Pakistan is unable to tackle these problems yet and these problems are generating other socioeconomic problems in the society like income level is falling, expenditure pattern are changing and health conditions are becoming poor rural as well as urban areas of Pakistan. Considering this, the present study is aiming to identify the effect of Environmental Quality on the Economic Status of Households (Income, Expenditure and Assets) in Multan District of Southern Punjab, Pakistan.

\section{Literature Review}

The studies relating to Environment and Income level are available in the Economic Literature using Time series or Panel data for various economies. Here, in this section, few of them are presented with brief discussion. Galzar, Sasa \& Rodjka (1992) designed the model to recover the Slovenian river water pollution in emergency situation. Their model is based on the pro-communication system and is derived from two relational databases using the Informix Sql relational data base management system. This study proves the relationship between the river water pollution and economic growth.

Taskin and Zain (2000) observed the environmental efficiency through kernel estimation. The study defines the relationship between GDP growth and environmental degradation. The efficiency of environment was investigated by Kuznet curve. This research uses environment efficiency indexes for high income and low income countries by using non parametric production frontier techniques and then shows environmental Kuznets relationship. The result shows the relationship between efficiency environment and per capita and income by using Kernel estimators.

Wheeler and Ben-Sholmo (2005) establish the relationship between socioeconomic status and local air quality and combined effect on respiratory health in the view of environment and health inequality. The research conducted the survey regarding the air quality, socioeconomic status in connection with the nitrogen dioxide, sulphur dioxide, benzene quality. Regression model were used to assess the associations between social classes, air quality. Ordinary least squares regression models were used to estimate the impact of social class and air quality on FEV. The study concludes that households of lower social class are living in area with poor air quality and these households are having more diseases like Lung problems, asthma prevalence.

Ewers (2006) explored the link between deforestation rate and the economic development. In this research, 103 countries were included that were classified as high-income, low income countries. High countries had low forest cover had the high rate of a forestation through the new plantations. On the other hand, low income countries had low area of forest. The study reveals that high income countries have highest rates of forestation due to plantations and they have low forest cover while low income countries have little forestation and they are intended to consume that portion of forest with high rate of forest cover.

Wahab et al. (2008) analyzed the management activities for drainage system on Egypt. This study showed the new concept of managing for existed face drainage system and maintaining crop production. The conclusion indicated that maintain of drainage system increased yields per unit land and whilst increased the irrigation water by $15-20 \%$. If water saving using controlled drainage in large areas is done 
then the potential for water saving in Egypt will be large.

Barrio and Loureiro (2010) presented the meta-analysis about forest by using contingent valuation. In this study, the marginal value of estimated different management programs that provide the different Kinds of forest goods and services. The data obtained from CV literature valuing ecosystem forest since 1990s. The results of the study reveal that recreational services, type of forest, location, survey mode and type of respondent decide about the willing to pay.

Hosonuma et al. (2012) examined the factors that were responsible of deforestation and forest degradation in developing counties. The study discovers that Asia and Africa has same tendency of deforestation while there is similar degradation in Latin America and Asia. There is Commercial Agriculture which is becoming the cause of deforestation and fuelwood collection, charcoal production and livestock grazing is also generating deforestation.

According to Khan and Rehman (2012), growth depends upon the technological and organizational growth. Without education and health the goal of development can not achieved. So those economies rapidly grow who invest on environment, education, and health sectors. In the Pakistan environmental sector have very low performance so this is why the human capital cannot produced. Not in Pakistan if we observe in India and other less developed countries both sectors health, education and health have very low position. It is also suggested to improve the skills of workforce by doing more investment in human capital so that marginal productivity of capital can be increased.

Alege and Ogundipe (2013) examined the relationship between economic growth and environmental quality by data taking data from World Development Indicators and World Governance Indicators over the period from 1970 to 2011. The study advised that strengthening institutional quality is necessary through ensuring adoption of clean technologies with the rise in income. Large Population Density is concluded as the base of cleaner environment in Nigeria with non-existence of EKC.

Omay (2013) examines the impact of income on air pollution and impact of GDP on Co2 Emission in Turkey using time series data from 1980 to 2009 by using regression Spline method. The study does not favor "EKC" hypothesis with inverted " $U$ " shaped curve in Turkey and concluded that there is Nshaped relationship between Co2 emission and economic growth.

Chiarazzo et al. (2014) examined the house value and pollution problem considering the local land quality, environment quality, and other facilities accessibility of other set the prices of real estates. The most of the variables is related with transport quality, air pollution, noise pollution, bath rooms, drainage system, schools distance, garage, garden rooms and train. All above variable play a vital role to set the real estate prices. It is concluded in the study that polluted and poor landscaped real estate/ properties/ land are having less demand due to such key environmental conditions.

Wang et al. (2016) explore the relationship between the income and $\mathrm{So}_{2}$ (Sulfer Dioxide) emission by investigation on Environmental Kuznets Curve (EKC) using provincial panel from 1990-2012. From the analysis, it was found that there was evidence for inverted U-Shaped curve using sulfur dioxide.

Resende et al. (2017) examined the valuation of ecosystem services to support the conservation of natural areas using primary data from 514 peoples and judged their willingness to pay. The outcome of the survey indicated the willingness to pay that was $\$ 7.16$ per year. It is also concluded in this study that 
per capita income, household size, interest in environmental issues and place of origin are motivating factors for willingness to pay.

\section{Data and Methodology}

\subsection{Data and Study Area}

This research adopted Primary source of data from urban and rural areas of Multan District using Multidimensional questionnaire. Multan is the $3^{\text {rd }}$ Largest city of Punjab Province, Pakistan. Geographically, Multan city lie on the east of the Chenab River, approximately Multan is in the center of the country. Multan city is the business hub of Southern Punjab. The biggest and famous recognition of the Multan city in the whole world, Multan is known as the city of Saints (Peer) Shrines. In the Multan city there is a large number of Shrines, Beautiful designed mosques, tombs. People from the rest of the world make the tour and visit the Multan city. Multan city is also known as the name "Madinah-TulAuliya. Total population is 3,116851 in numbers according to the population census and the literacy rate for urban area is $72 \%$ and $41 \%$ in the rural areas. $53.2 \%$ is male literacy rate and $32.28 \%$ is female literacy rate of the Multan city. Multan district is also known as the Siraiki area. The general language of Multan district natives or inhabitant is the Siraiki.

The researcher has conducted the direct interview of almost 401 households through questionnaire. The researcher inquired one by one from the head of household for desired information. Simple random sampling technique and stratified random sampling technique is followed for the collection of data. Estimation is done by adopting simple least square method (Ordinary Least Square Method-OLS) through E-Views-9.1 software.

\subsection{Model Specification}

Taking into account the objective of the research that is to discover the effect Environmental Variables on Economic Status (Income, Expenditure and Assets) of households, the subsequent model is presented;

$$
\text { Economic Status }=f\left\{\begin{array}{c}
\text { Age,Education, Location, Green Belt Area, } \\
\text { Female to Male Ratio, Credit Availability, } \\
\text { Formal Employment Status, Clean Water, } \\
\text { Sui Gas Availability, Housing Condition } \\
\text {, Health Facilities, Irrigation Facilities }
\end{array}\right\}
$$

The same model may be written in equation form;

$$
E C S T=\left[\begin{array}{c}
\beta_{0}+\beta_{1} A G E+\beta_{2} E D U+\beta_{3} L O C+\beta_{4} G B T+\beta_{5} F M R+\beta_{6} C R A+ \\
\beta_{7} E M P+\beta_{8} C L W T+\beta_{9} E N C K+\beta_{10} H C O N+\beta_{11} H L F+\beta_{12} I R R+u_{i}
\end{array}\right]
$$

Where,

$\begin{array}{lll}\text { ECST } & \quad \begin{array}{l}\text { Economic Status of Households } \\ \text { (Income, Expenditure, Assets) }\end{array} \\ \text { AGE }= & \text { Age of Household Head } \\ \text { EDU }= & \text { Education of Household Head } \\ \text { LOC }= & \text { Location/ Area of Residence } \\ \text { GBT }= & \text { Green Belt Area } \\ \text { FMR }= & \text { Female to Male Ratio } \\ \text { CRA }= & \text { Credit Availability to the Respondent } \\ \text { EMP }= & \text { Employment Status of Respondent } \\ \text { CLWT }= & \text { Availability of Clean Drinking Water }\end{array}$




$\begin{array}{ll}\text { ENCK }= & \text { Availability of Sui Gas Energy for Cooking } \\ \text { HCON }= & \text { Housing Condition } \\ \text { HLF }= & \text { Health Facilities to the Respondent } \\ \text { IRR }= & \text { Irrigation Facilities to the Respondent }\end{array}$

There are so many factors that may have an effect on the household economic status. But in the present study, few Economic, Demographic and Environmental Quality variables are described along with unit of measurement and expected relationships in table 1.

Table 1: $\quad$ Description of Variables

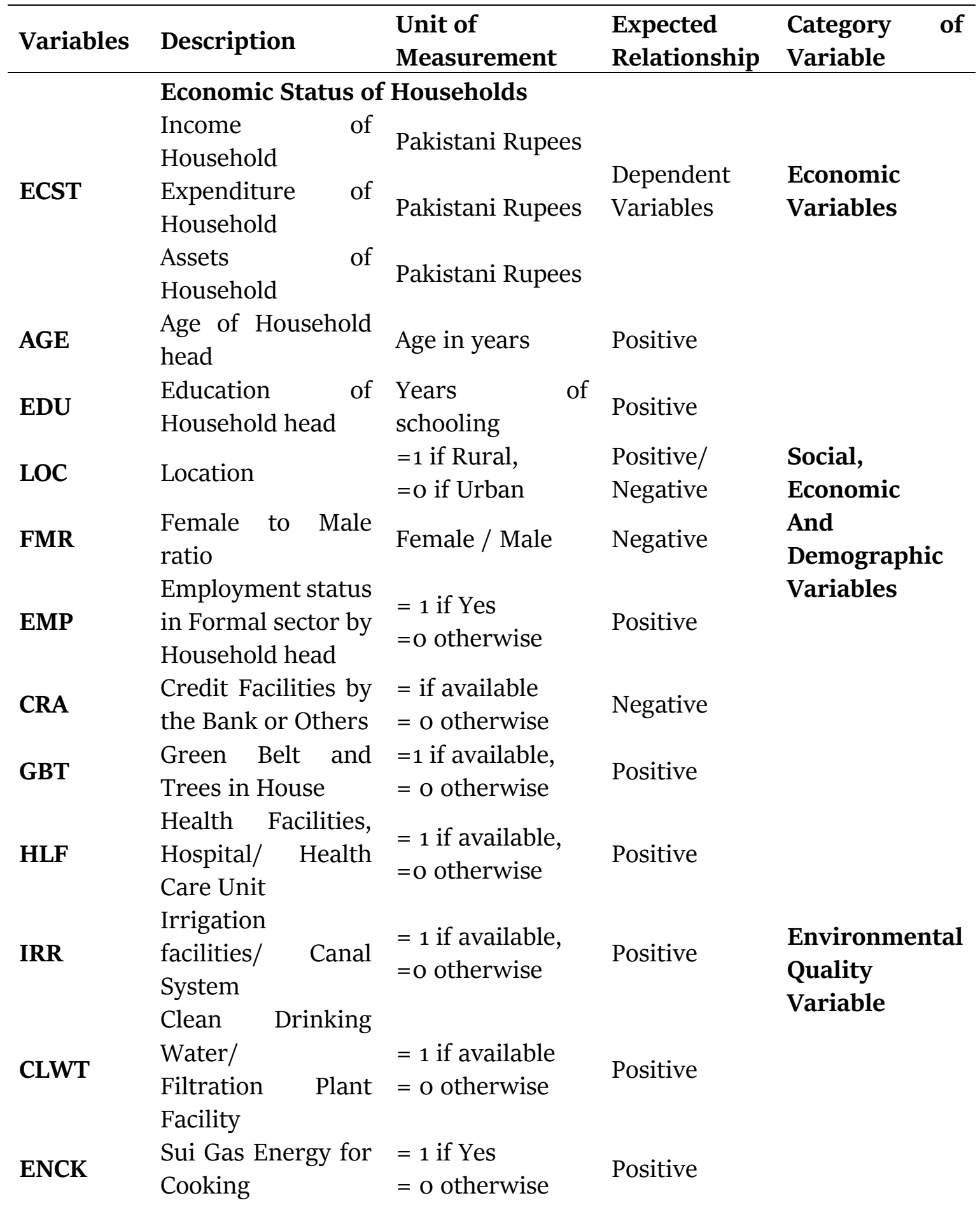




$\begin{array}{llll} & \text { House Condition, } & & \\ \text { Constructed } & =1 \text { if Yes } & \\ \text { HCON } & \text { Material } & =0 \text { otherwise } & \\ \text { (Cemented, } & & \\ & \text { Tiled, Pakka etc) } & & \end{array}$

\section{Results and Discussions}

The econometric results of Economic Status Models are reproduced in table 2 in which three models are presented considering Income, Assets and Expenditure of Households in $2^{\text {nd }}, 3^{\text {rd }}$ and $4^{\text {th }}$ columns while first column shows names of variables accordingly.

Age is an important variable determining the Income, Expenditure and Assets of the Households in a way that as households are becoming more experienced they may be able to get higher economic status in the society. In the results, Age of Household Head is positively linked with Income, Assets and Expenditure of the households but the coefficients values are insignificant in all the models.

Education of Household Head is another variable that may be a source of higher Economic status of the Households. As households are more educated, there is possibility that they can be engaged with higher Earning opportunities. In the study, the sign of Education is also positive with Income, Assets and Expenditure of Households but the significant coefficient is estimated only with Income model at 5 percent. It may be interpreted as Income of Households will increase by 1110 rupees due to education of one additional year approximately.

The result of location of respondent shows the rural areas residence of respondent which shows that if respondent lives in rural area so there will be opportunities of less earning and less spending. The reason may be that there are less earning opportunities are available in rural areas as jobs are more available in urban areas and there are more markets available in urban areas so spending options are also less in rural areas. But on the other side, households living in rural areas can be able to make more assets as compared to households living in urban areas because the study area is considered as agricultural area which is fully packed with rural areas around the city. The coefficient value of Location is significant for Assets and Expenditure models.

Table 2: Econometric Results of Economic Status Models

\begin{tabular}{llll}
\hline Variable & \multicolumn{1}{l}{ Income } & Assets & Expenditures \\
\hline Constant & 17.92 & 6.45 & $20.91^{* * *}$ \\
Social, Economic and Demographic Variables & \\
Age & 0.03 & 0.12 & 0.02 \\
Education & $1.11^{* *}$ & 0.51 & 0.05 \\
Location & -1.95 & $10.06^{* * *}$ & $-1.79^{*}$ \\
Female to Male & $-8.11^{* * *}$ & $-5.32^{* * *}$ & $-2.49^{* * *}$ \\
Formal Employment & $9.25^{* * *}$ & 1.85 & 0.94 \\
Credit Availability & $-7.23^{* * *}$ & 0.87 & -0.25 \\
Environmental Variables & & & \\
Green Belt \& Trees & $16.82^{* * *}$ & $4.04^{*}$ & $2.06^{* * *}$ \\
Health Facilities & $12.07^{* *}$ & $7.80^{* *}$ & 0.13 \\
Irrigation Facility & 2.12 & $8.11^{* * *}$ & $0.71^{* * *}$
\end{tabular}




\begin{tabular}{llll}
\hline Clean Drinking Water & $1.22^{*}$ & 6.23 & $1.68^{* *}$ \\
Sui Gas Availability & 1.86 & $4.49^{* * *}$ & $3.23^{* * *}$ \\
Housing Condition & 3.48 & $11.43^{* * *}$ & $5.19^{* * *}$ \\
R-squared & 0.368377 & 0.363770 & 0.663479 \\
Adjusted R-squared & 0.348690 & 0.343679 & 0.652963 \\
F-statistic & 18.71174 & 18.10573 & 63.09064 \\
Probability & & & \\
(F-statistic) & 0.000000 & 0.000000 & 0.000000 \\
\hline
\end{tabular}

Source: Author's Calculations

Female to Male ratio variable is highly significant with Economic Status of Households (Income, Assets and Expenditure Models) with significant coefficients. It shows that economic status of households would not be improved if there are more females as compared to male in the household. The reason is very simple, females are generally considered in the category of dependents so they may not be able to participate in economic activities. In the study, income of household will fall by 811 rupees if this ratio increases by one point approximately.

Formal Employment is another variable which is statistically significant and positive relation with the Income only. Formal sector is earning a fix and regular monthly income and people who know their income can manage well in their income. For Assets and Expenditure models, the sign is positive but statistically not significant. Its interpretation may be that income of household will increase by 925 rupees if household is working in formal sector.

Availability of Credit Facility is one more variable which may be perceived as the source of Higher Income if this credit is utilized in appropriate way. In the present analysis, the sign attached with this variable is opposite and negative showing that Income of Households will fall if credit facilities are available in the study area which is quite opposite to the expectations. The coefficient is significant for Income model only and may be explained as availability of credit facility is resulting in reduction of income by 723 rupees. It may be due to unnecessary and extra expenditure by the households of the study area.

Considering Environmental Variables in the study, Green Belt is the most important variable which is representative of the improvement of environmental quality in the study area. The study finds positive influence of availability of green belt in the study on Income, Expenditure and Assets of Households. If environmental quality is improved so the people will be mentally, socially and physically healthy so they may be able to take part in economic activities with more devotion and in better so their economic status will be improved. If green belts are available so households will be able to earn 1682 rupees per month more as compared to other areas. The coefficient values for all the models are statistically significant as well.

Health Facilities is another variable relevant to environmental variable in the study area. The study obtains this variable as positively linked with Economic Status of Households (Income, Expenditure and Assets of Households). If health facilities or hospitals are improved in the study area so the people will be mentally, socially and physically more healthy so they may be able to take part in economic activities with more devotion and in better so their economic status will be improved. Approximately, availability of health facility or hospital in the study area may be able to enhance income by 1207 rupees per month. The coefficient values for income and assets models are statistically significant but for 
expenditure model it is insignificant.

Availability of Irrigation Facility may be a source of getting good economic status by the households. If agricultural lands are irrigated with canals or with sweat water so their production from agriculture sector will be improved and they may be improve their economic status (Income, Assets and Expenditure). In this study, this variable is significant for Assets and Expenditure models only.

Clean Drinking water Facilities is the most imperative variable relevant to environmental variable in the study area. This variable is obtained as positive with Economic Status of Households (Income, Expenditure and Assets of Households) in the present study. If people are provided with Clean Drinking water so their health will be improved and they may be able to take part in economic activities more actively with devotion and in response their economic status will be improved. Approximately, availability of clean drinking water in the study area may be able to enhance income by 122 rupees per month and expenditure by 168 rupees. The coefficient values for income and expenditure models are statistically significant but for assets model it is insignificant.

The availability of Sui Gas as the Source of Energy in the study area is included as environmental concerns. It is perceived as generating less pollution in the environment. If other sources like wood or kerosene oil is used as the source of energy in the households so there is possibility of more pollution and environmental quality will become poor in response. In this respect, availability of Sui Gas is taken in this study which is positively connected with economic status of households with statistically significant coefficients in models of assets and expenditure. It reveals that environmental quality will be improved if people are utilizing Sui Gas as source of energy so the people will be mentally, socially and physically healthy and they may be able to take part in economic activities with more devotion and in better way to improve their economic status.

The Housing Conditions in the study area is another variable portraying environmental condition of the household. If people are living in Cemented and Tiled houses (With Tiled Wash Room) so their environment of household will be improved and they will be in a good health conditions so they will be mentally, socially and physically more healthy as compared to people living in Kacha Houses and they may be able to take part in economic activities with more devotion and in better way to improve their economic status. This variable is significant in the model of Assets and Expenditure with positive coefficient value.

\section{Conclusions and Policy Implications}

The present study is aiming to identify the effect of Environmental Quality on the Economic Status of Households (Income, Expenditure and Assets) in Multan District of Southern Punjab, Pakistan. The study has conducted the direct interview of almost 401 households through questionnaire. Simple random and stratified random sampling technique is followed for the collection of data. Estimation is done by adopting simple least square method (Ordinary Least Square Method-OLS).

In this study, Income, Assets and Expenditure of Households are believed as the variables of Economic Status while Green Belt and Trees in the House, Health Facilities/ Hospitals, Irrigation Facilities/ Canal System, Clean Drinking Water, Sui Gas for Cooking and Housing Condition (Cemented/ Tiled/ Pakka) are supposed to be the variables for Environmental Quality.

The results of OLS demonstrates that Age, Education, Formal Employment, Green Belt \& Trees, 
Health Facilities, Irrigation Facility, Clean Drinking Water, Sui Gas Availability and Housing Condition are reported as the basis of Higher Income/ Expenditure of Households while Rural Area, Female to Male ratio and credit availability are reducing Income/ Expenditure of Households. On the other side, Age, Education, Rural Location, Formal Employment, Credit Availability, Green Belt \& Trees, Health Facilities, Irrigation Facility, Clean Drinking Water, Sui Gas Availability and Housing Condition are the origin of increasing Assets of Households while Female to male ratio is reducing Assets.

On the basis of Econometric Results, it may be suggested that there is need to concentrate on Green Belts \& plantation in urban areas along with Good Health Facilities, Well Constructed Housing, Canal System for improving Economic Status of Households in Rural as well as Urban Areas. Govt. should provide Clean Drinking Water and Natural Gas Facility to all citizens to improve environmental quality of urban \& rural areas.

\section{References}

Wheeler, B. W. and Ben-Shlomo, Y. (2005). Environmental equity, air quality, socioeconomic status, and respiratory health: a linkage analysis of routine data from the Health Survey for England. J Epidemiol Community Health, 59, 948-954.

Resendea, F. M., Fernandesa, G. W., Andraded, D. C. and Néderd, H. D. (2017). Economic valuation of the ecosystem services provided by a protected area in the Brazilian Cerrado: application of the contingent valuation method. Braz. J. Biol., 77 (4), 762-773.

Khan, M. A. and Rehman, H. (2012). Regional Disparities in Human Capital: The Case of Pakistan. Pakistan Economic and Social Review, 50 (1), 57-69.

Shamrukh, M. and Abdel-Wahab, A. (2008). Riverbank filtration for sustainable water supply: application to a large-scale facility on the Nile River. Clean Techn Environ Policy, 10, 351-358

Hosonuma, N., Herold, M., Sy, V. D., De-Fries R. S., Brockhaus, M., Verchot, L., Angelsen, A. and Romijn, E. (2012). An assessment of deforestation and forest degradation drivers in developing countries. Environmental Research Letters, 7, 1-12.

Omay, R. E. (2013). The Relationship between Environment and Income: Regression Spline Approach. International Journal of Energy Economics and Policy, 3, 52-61.

Ewers, R. M. (2006). Interaction effects between economic development and forest cover determine deforestation rates. Global Environmental Change, 16, 161-169.

Chiarazzob, V., Olioa, L. D., Ibeasa, A. and Ottomanellib, M. (2014). Modeling the effects of environmental impacts and accessibility on real estate prices in industrial cities. Procedia - Social and Behavioral Sciences, 111, 460-469.

Wang, Y., Han, R. and Kubota, J. (2016). Is there an Environmental Kuznets Curve for SO2 emissions? A semi-parametric panel data analysis for China. Renewable and Sustainable Energy Reviews, 54, 1182-1188. 